\title{
Hispanic College Students Library Experience
}

Risa Lumley, California State University, USA

Eric Newman, California State University, USA

Haakon T. Brown, California State University, San Bernardino, USA

\begin{abstract}
This study looks at undergraduate Hispanic students' interpretations and current perceptions of the academic library's purpose, usefulness and value. What are the reasons to use the library? What are the barriers to use? This study will examine academic libraries' move toward electronic library materials and what it means for Hispanic students. The results of this study will help academic libraries at Hispanic Serving Institutions to better understand how they are currently being perceived and what they need to do to market themselves and their collections to better serve Hispanic students.
\end{abstract}

Keywords: Library; Information; Hispanic; Students; Technology

\section{INTRODUCTION}

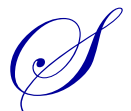

econd generation Hispanic students comprise a large and growing student population in the United States and are more likely to attend college than are their first generation counterparts. However, Hispanics are at the highest risk for school failure once enrolled, especially during their first year in college (Haras, Lopez, $\&$ Ferry, 2008). A number of studies in the library literature have linked student persistence in higher education to library usage (Long, 2011). Information literacy is a core academic skill in college curricula, which typically include formal writing tasks such as the research paper. The research paper is supported by research activities such as evidence gathering, critical evaluation, and referencing sources (Haras, Lopez, \& Ferry, 2008). Students who use the library frequently, seek assistance from librarians, and demonstrate higher levels of information literacy are more likely to earn baccalaureate degrees in four to six years than their counterparts who do not use the library (Long, 2011).

Whether consciously or unconsciously, the policies and procedures of most academic libraries in the U.S. reflect Anglo cultural values and systems. This is observed in the language of their signage, the details of their book collections, the level of noise that is tolerated, the types of activities that are encouraged by the library staff, and the demeanor of library staff (Long, 2011). In addition, Hispanics are underrepresented in the field of librarianship (4.6 percent of all librarians), and cannot provide cultural reinforcement for the large number of Hispanic library patrons (Adkins \& Hussey, 2006). This is especially problematic because librarians serve as the gatekeepers between library users and information. They mediate the relationship between people and the library collections by interpreting the user's needs according to their own experience and then referring the user to the best resources available in the library (Long, 2011).

What does it mean for students to "use the library" at a time when more and more of the library's resources can be accessed online at any time from any place? Can some of the cultural barriers to library use be mediated by online access to library resources? What are the implications of moving more and more services and resources online for Hispanic students, whose university success is correlated with personal, consistent, face-to-face interaction with faculty, staff and other students (Salinas, 2008)? These were the questions that motivated us to administer a "Communication Improvement Survey" to incoming freshmen at our campus as a pre-test to begin to make sense of the observed lack of engagement between our mostly Hispanic student population and our primarily online campus library. Our survey questions addressed demographics, access to, and preference for electronic 
communication platforms, where students go to find information, attitudes toward libraries in general, and parental/guardian education levels.

\section{DEMOGRAPHICS}

The students who responded to our survey self-identified as primarily Hispanic (83\%), 18 years old (93\%), and female (65\%). In our survey instrument and in this paper, we use the term Hispanic, while acknowledging that it is often used interchangeably with the term Latino, even by the census bureau. In this paper, students referred to as Hispanic are those individuals whose heritage, nationality group, lineage, or country of birth, or that of their parents or ancestors before their arrival in the United States, is Cuban, Mexican, Puerto Rican, or South or Central American, regardless of race.

Most of our students are the first generation in their family to attend college. Among those who knew what level of education their father reached (11\% did not know), $80 \%$ indicated high-school or less, whereas for mothers (6\% did not know) that statistic was even lower 67\% indicated high school or less. Parental education level can be seen as a proxy for socioeconomic status, which impacts not only student financial support, but also the ability of parents to provide assistance to students navigating unfamiliar academic environments.

The language that Hispanic students grow up speaking at home is important to any discussion of academic literacy, including information literacy and library skills. Our students reported speaking either Spanish (51\%) or English (40\%) as the primary language at home. Many Hispanic students entering their first year of college are still learning English, despite the fact that they are native born, may speak English at home, and have received much of their K-12 education in the United States. This is because Hispanic students are often treated as ESL learners, placed in low-track writing classes, and not exposed to academic writing and research conventions in high school (Haras, Lopez, \& Ferry, 2008). They may not come to college ready to read and write using academic English.

\section{ELECTRONIC ACCESS}

Our survey asked students to indicate all means by which they communicate online, whether on a laptop (68\%); home computer (25\%); cell phone (88\%); public internet connection $(7 \%)$ or private internet connection (14\%). The results reflect the recent trend of technology "leapfrogging" among California's Hispanic community where only $50 \%$ of adults have broadband access at home, yet 70\% own smartphones (McCabe, 2013).

While popular rhetoric would have us believe that all young people are generally savvy with digital media, data clearly show that considerable variation exists even among fully wired college students when it comes to understanding various aspects of internet use. Add to this the fact that Hispanic students are more likely to be accessing the internet via smartphones, which default to mobile internet sites with reduced functionality, and the issue becomes even more complex. Students of lower socioeconomic status, women, students of Hispanic origin, and African Americans exhibit lower levels of online know-how than others (Hargittai, 2010). Also students whose parents have no more than a high school degree visit a lower diversity of sites, and engage in fewer informationseeking activities online on a regular basis than those whose parents have a college degree (Hargittai, 2010). This aligns with Salinas' finding (2008) that Hispanic students do not have strong networks of social support to assist them in accessing digital information. In much the same way that students can speak English for years without developing academic literacy, students can also be computer users for years and still lack basic computer skills or understanding, which may result in an inability to access information that may be critical to their academic success (Salinas, 2008).

\section{INFORMATION SEEKING BEHAVIOR}

The purpose of our next survey question was to elicit information about where these students, who have not yet started college, turn to find information for classroom assignments, job and career leads, and general information. The responses of our students were not surprising, with search engines such as Google, being the overwhelming place that students turn to for information $87 \%$ of the time, followed by asking friends and family $63 \%$, with libraries utilized less than $30 \%$ of the time. 
Study after study has found that undergraduates across all demographics favor starting a research assignment by using a Web search engine rather than a library database, and that if they encounter barriers to digital information they would turn to friends or classmates as their first source of assistance (Salinas, 2008). Hispanic students in particular, tend to seek assistance from people with whom they have a clearly defined relationship and know from previous interactions, and these students rarely ask for help from someone based on their position (e.g., tutor, librarian, instructor, and so forth). In other words, Hispanic students do not ask strangers for help, and unfortunately, the reference librarian is considered exactly that by most students: a stranger with an uncertain role (Duke \& Asher, 2012).

A further explanation for why many Hispanic students do not ask for help more often, especially from professors, librarians, and others in a position to help them, is that these students expect to work independently and without assistance, since that is what they have done thus far in their education (Duke \& Asher, 2012). These students have spent years learning to navigate between their own culture and the dominant American culture, and their persistence in postsecondary education is a sign that they have done so successfully (Adkins \& Hussey, 2006).

\section{Attitudes Toward Libraries}

Our next survey question asked students to rate their feelings toward libraries in general, along a scale from worthless to valuable; useless to useful; negative to positive; unimportant to important; and outdated to modern. Results indicated that students feel that libraries are outdated, and yet at the same time, they feel that libraries are important. Because the survey was administered in the library and we were asking about the library, this question is biased ( $85 \%$ of the ratings were scaled as a 6 or 7 on the 7 point scale.. Also, since we were asking incoming freshmen students about libraries in general, their answers likely reflect their feelings toward public libraries and recent school library experiences, rather than feelings toward academic libraries.

Previous studies have shown that the role of the academic library is less distinct to Hispanic students than the role of the public or school library, and that they experience some confusion in their relationship with the academic library (Long, 2011). It is not necessarily obvious to these students how academic library collections, online resources, and services are different from public library resources and services (Duke \& Asher, 2012). However, Hispanic students have very definite ideas about appropriate behavior in the university library building. For Hispanic students the academic library is viewed as a source for information, a place for quiet study, and, to a much lesser degree, a place for "social" study; in contrast, they had more positive attitudes toward social activity at the public library. To Hispanic students, the academic library existed to facilitate schoolwork and to reinforce the dominant culture, while the public library was viewed as a community resource reflecting the local culture much like a park or a museum (Adkins \& Hussey, 2006). In this way, public libraries have done a better job of recognizing and respecting the process of acculturation, which takes place as generations gradually integrate and adopt elements of the dominant culture, while keeping facets of the old. Academic libraries on the other hand, may be viewed by Hispanic students as demanding assimilation, or the complete denial of their cultural identity (Corona \& McCabe, 2011).

Our campus library is comprised of a very small physical collection and a large number of computers to facilitate access to our vast digital collection. As our previous survey question about information-seeking behavior indicated, many of our incoming students have not previously used an online library, and consequently they may not even understand how these resources differ from the internet resources they are accustomed to using. Students across all demographics feel more confident in their ability to use the general internet than library databases, and Hispanic students feel even less confident in using library databases than other students (Salinas, 2008). However, unlike library reference services, computers provide access to information without direct mediation of a librarian or other staff (Adkins \& Hussey, 2006), which may initially appeal to Hispanic students and others who feel culturally marginalized.

Although our survey did not specifically ask about attitudes toward library staff, previous studies have demonstrated that many students are unaware of librarians as having relevance to their studies at the university, and some Hispanic students are not even familiar with the term librarian. Students do not seem to differentiate between librarians and paraprofessionals; the main distinction between staff at the academic library is between adult 
librarians and student workers (Adkins \& Hussey, 2006). Few of the students in these studies had approached a librarian for assistance. Generally, the students had the impression that library staff was reasonably accessible should they need assistance, but they did not feel that assistance was warranted in most instances (Long, 2011), and they only vaguely understood how such assistance could strengthen the quality of their schoolwork. Most of the encounters students have with librarians are the instruction sessions taught by librarians as part of the general education curriculum (Long, 2011). Students simply have little opportunity to become familiar with individual librarians and to learn how these librarians can help (Duke \& Asher, 2012).

\section{CONCLUSIONS}

Academic librarians are not doing a good enough job at explaining and demonstrating their purpose to Hispanic students. Multiple, hands-on, library instruction sessions would greatly benefit all students, and Hispanic students in particular, who may only seek assistance from library staff when there is an established, trusted, relationship. Teaching faculty can assist librarians by inviting them to class and making personal introductions to Hispanic students, so that they will feel more comfortable approaching librarians for assistance.

Likewise, it is not enough to tell Hispanic students about online library resources and expect that they will use them. Hispanic students are less likely to have internet connected desktop computers in their home, and may rely on Smartphones for internet access, making the use of online library materials difficult from off-campus. Mobilefriendly web sites and library apps should be refined, and library lending of laptops, as well as on-campus computer labs and computer support should be specifically marketed to Hispanic students. Librarians must be proactive in seeking out students and developing relationships and offering to explain and demonstrate online library resources at the time of the students' immediate need.

Academic libraries can encourage Hispanic students to enter and use the library space by making the environment culturally welcoming, by hiring a more diverse staff, and by highlighting multicultural collections, and displaying library material and art from different cultures. If academic libraries want to effectively engage Hispanic students, they have to understand and respect the various levels of acculturation of those students.

\section{AUTHOR INFORMATION}

Risa Lumley is the Librarian at the California State University San Bernardino Palm Desert Campus. She received her Bachelor of Science in Linguistics and Russian Studies from the University of California Riverside and her Master of Arts in Library and Information Science from the University of Iowa.

Eric Newman is a Professor of Marketing in the College of Business and Public Administration at California State University and is currently assigned to the Palm Desert Campus. He received his Bachelor of Science and MBA from the University of Montana and a Ph.D. from Washington State University.

Haakon Brown is an Assistant Professor of Marketing at California State University, San Bernardino. He holds a Ph.D. in marketing from the Kellogg School of Management at Northwestern University. His research interests include attitudes and consumer behavior, consumer self-control, cultural effects on consumption, and the consumption of sport. Prior to his academic pursuits, Haakon spent a number of years working in consulting. He also holds an MBA from the MIT Sloan School of Management. E-mail: hbrown@csusb.edu

\section{REFERENCES}

1. Adkins, D., \& Hussey, L. (2006). The Library in the Lives of Latino College Students. The Library Quarterly, 76(4), 456-480.

2. Corona, R., \& McCabe, M. B. (2011). Acculturation to Marketing to Latinos in the US. Journal of Business \& Economics Research, 9(9), 67-70.

3. Duke, L. M., \& Asher, A. D. (2012). College Libraries and Student Culture: What we Now Know. Chicago: American Library Association. 
4. Haras, C., Lopez, E. M., \& Ferry, K. (2008). (Generation 1.5) Latino Students and the Library: A Case Study. The Journal of Academic Librarianship, 34(5), 425-433.

5. Hargittai, E. (2010). Digital Na(t)ives? Variation in Internet Skills and Usage among Members of the "Net Generation". Sociological Inquiry, 80(1), 92-113.

6. Long, D. (2011). Latino Students' Perceptions of the Academic Library. The Journal of Academic Librarianship, 37(6), 504-511.

7. McCabe, M. B. (2013). U.S. Hispanics Go Mobile: Adoption and Marketing Engagement Trends. IJMM, $8(2), 67-74$.

8. $\quad$ Salinas, R. (2008). The Digital Divide Goes to College: Latino Undergraduates and Barriers to Digital Information. Los Angeles: University of California. 


\section{NOTES}

